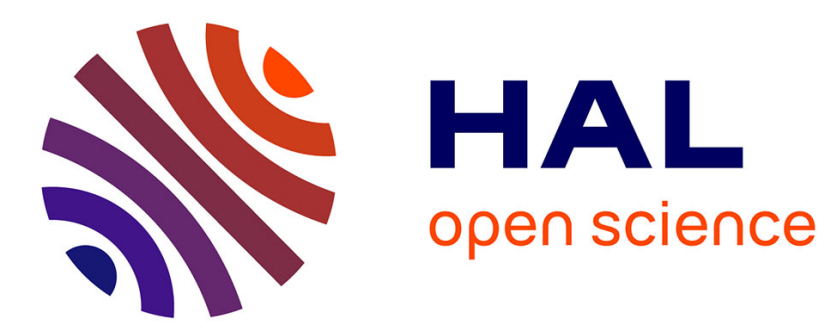

\title{
Dynamic voluntary contributions to a discrete public good:Experimental evidence
}

\author{
Pavel Diev, Walid Hichri
}

\section{To cite this version:}

Pavel Diev, Walid Hichri. Dynamic voluntary contributions to a discrete public good:Experimental evidence. Economics Bulletin, 2008, 3 (23), pp. 1-11. halshs-00282669

\section{HAL Id: halshs-00282669 \\ https://shs.hal.science/halshs-00282669}

Submitted on 21 Apr 2009

HAL is a multi-disciplinary open access archive for the deposit and dissemination of scientific research documents, whether they are published or not. The documents may come from teaching and research institutions in France or abroad, or from public or private research centers.
L'archive ouverte pluridisciplinaire $\mathbf{H A L}$, est destinée au dépôt et à la diffusion de documents scientifiques de niveau recherche, publiés ou non, émanant des établissements d'enseignement et de recherche français ou étrangers, des laboratoires publics ou privés. 


\title{
Dynamic voluntary contributions to a discrete public good: Experimental evidence*
}

\author{
Pavel Dieva and Walid Hichri ${ }^{\mathrm{b}}$
}

\begin{abstract}
We experiment a mechanism for the provision of a discrete public good where individuals are allowed to update upwards their contribution during a fixed time interval. Experimental evidence shows that the subjects are increasing their contributions in order to finance the cost of the good. The public good is financed more frequently when its cost is low relative to the social willingness to pay.
\end{abstract}

Keywords Public Goods, Experiments, Voluntary contributions, Dynamic contributions

JEL Classification: C92; $\mathrm{H}_{4} 1$

\section{Introduction}

Consider the following example of a real situation captured by our framework. Ph.D. students in a research lab want to jointly buy a new workstation. In order to buy it at a special tariff they must order it before the end of the week. During the current week they can at any moment write a check towards the purchase of the machine. The director of the lab collects the checks and announces the total amount collected each time he receives a check. A student that already wrote one or several checks can write another one at any time. At the end of the week, if the sum of the checks covers the cost, the workstation is bought. If the total amount is larger than the cost the director can dispose at will of the extra amount (no refund of extra contributions). If the total amount is less than the cost the checks are destroyed (refund of contributions). In this paper we perform an experiment for this situation.

Theory says that, in itself, dynamic structure of contribution to a public good cannot lead to an efficient outcome, see Fersthman and Nitzan (1991),

${ }^{*}$ We are indebted to Christophe Deissenberg and Alan Kirman for their supervision. We also thank Jordi Brandts and Antoni Bosh for making the LeeX available for us.

The views expressed here are those of the authors and do not necessarily reflect those of the Banque de France

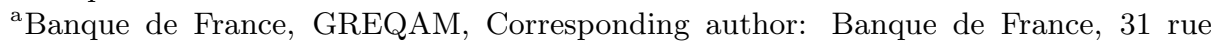
Croix des Petits Champs, 75049 Paris Cedex 01, France, Tel: +33(0)1.42.92.91.48 Fax: 33(0)1.42.92.49.50, e-mail: pavel.diev@banque-france.fr

${ }^{\mathrm{b}}$ GATE, Université Lumière Lyon 2 
Admati and Perry (1991), Gradstein (1992). The reason for negative results is that introducing dynamics allows individuals to free ride upon future contributions. This can be counteracted by assuming some form of punishment for free riders. For example, Marx and Matthews (2000) assume that the individuals commit to stop contributing if some individual contributes 0 in the current period. In our paper the punishment stems from the introduction of a fixed contribution period and a discrete public good. That is, there is no benefit from contributing if a given total amount is not reached and individuals cannot delay infinitely their contribution if they want to obtain some positive gain.

With regard to the experimental analysis of the dynamic public goods games the experiment in our paper presents similarities with the one in Dorsey (1992). Dorsey is interested in the relationship between the production technology of the public good and the amount collected, while we are mainly concerned with the efficient provision of the discrete public good. As in our paper, Dorsey allows the individuals to update their contribution during a fixed period. He uses linear public good production technologies which are continuous save for the following: if a given minimum amount of total contributions is not reached, the good is not provided at all, but the individuals are not refunded. There are two types of possible updates, increase or decrease. All individuals are originally given the same amount of (experimental) money - that is, they have identical WTP. By contrast, in our paper, we allow only increasing updates. We have a binary production function: either the good is produced in a given amount, or it's not produced at all. The individuals do not pay anything if the good is not provided and individuals are originally given different amounts of (experimental) money - that is, they have heterogeneous WTP.

Another related experimental paper is Levati and Neugebauer (2004). The authors consider a situation where the contributions are increasing at a fixed rate (English clock mechanism) and an individual can decide to stop contributing (i.e. exit the game) at any moment, and never contribute again. The decision to stop contributing is observed by the others. In contrast, in our paper, an individual can increase his contribution freely, and can only see the total amount collected but not each individual's contribution. Furthermore, Levati and Neugebauer assume identical WTP which are common knowledge, and a linear production function. In contrast, we assume heterogeneous WTP which are private information, and a discrete public good. 


\section{Experimental design}

The experiments are conducted by groups of four subjects, $n=4$. Two of the subjects are endowed with 100 tokens (i.e. experimental money) and the two others with 200 tokens, $W T P_{i}=\{100,200\}$. The endowments are private information. As in Hichri (2004) we run two treatments with different levels of social surplus. In the first treatment the cost of provision of the public good, $c$, represents $60 \%$ of the sum of the individual WTP $\left(\sum_{i=1}^{4} W T P_{i}=600\right)$, that is, the cost of provision is 360 tokens. ${ }^{1}$ In the second treatment the cost $c$ represents $80 \%$ of the sum of the WTP, that is, 480 tokens. $^{2}$ The time interval for contribution, $T$, is fixed to 90 seconds.

The experiment was run in January 2004 at LeeX (Laboratori d'Economia Experimental), University Pompeu Fabra in Barcelona. Each treatment included two experimental sessions of about one hour and a quarter. In each session we set three independent groups. This gives six independent statistical observations per treatment and requires 24 subjects per treatment ( 48 for the whole experiment). All of them were students selected randomly on the campus.

Each group played one practice period, followed by 20 paying periods. At the end of each period each subject was informed about the number of tokens he had earned. The number of subjects in a group, $n$, the provision cost, $c$, the length of the time interval, $T$, and the number of experimental periods was common knowledge. At the end of the session, a questionnaire was distributed to subjects.

The experiment was computerised. We used as software z-Tree, developed by Fischbacher (1999). At the beginning of each session, subjects were affected randomly to each computer. The experimenter read instructions loudly $^{3}$. Any questions were answered publicly. During the experiment communication was forbidden.

Subjects were paid privately and in cash at the end of the experiment. The payment of a player was equal to the amount of tokens he won converted into euros according to the rate 100 tokens $=1$ euro plus 6 euros as show up fees.

\footnotetext{
${ }^{1}$ Note that in the first treatment equal cost sharing imply that every subject has to pay 90 tokens, which is compatible with individual rationality.

${ }^{2}$ In the second treatment equal cost sharing imply that every subject has to pay 120 which is not compatible with the individual rationality of individuals with $W T P_{i}=100$.

${ }^{3}$ Instructions and a screenshot are available upon request.
} 

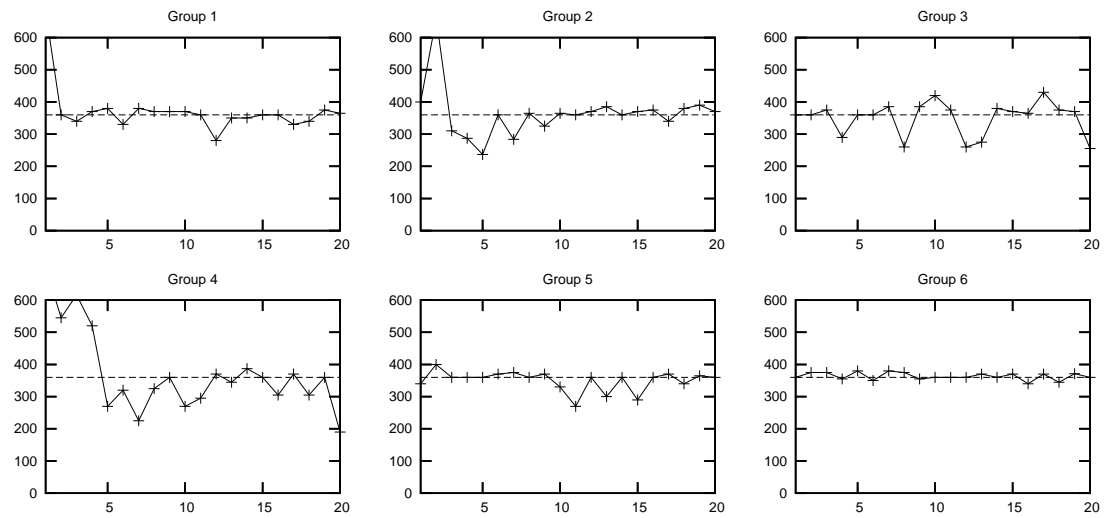

Figure 1: Contribution of each group over the 20 experimental periods (low treatment)

Table 1: Efficiency ratio (low treatment)

\begin{tabular}{|c|c|c|c|c|c|c|c|}
\hline & Group 1 & Group 2 & Group 3 & Group 4 & Group 5 & Group 6 & Average \\
\hline \hline$E f$ & 0.60 & 0.80 & 0.73 & 0.40 & 0.67 & 0.73 & 0.66 \\
\hline
\end{tabular}

\section{Results}

We are primary interested on the ability of the mechanism to provide efficiently the public good. A second question is: how do individuals behave during the interval of 90 seconds; in particular do they increase their contributions? To study the efficiency of the mechanism, we look on the total amount of contributions after 90 seconds and we construct an index, denoted $E f$, representing the ratio of the number of times a group succeeded in contributing an amount sufficient for providing the public good $(\geq c)$ over the total number of playing periods.

\subsection{Low threshold treatment $(c=360)$}

From Figure 1 we observe that in the first experimental periods some subjects (groups 1, 2 and 4) contribute big amounts, bigger than their WTP for instance. The reason is that they have not understood the game. Because their payoff was negative, they quickly learned not to contribute more that their WTP. Thus, we dropped out the first 5 periods from the analysis of the results, considering them as learning periods. The ratio $E f$ was computed over the 15 last periods. 

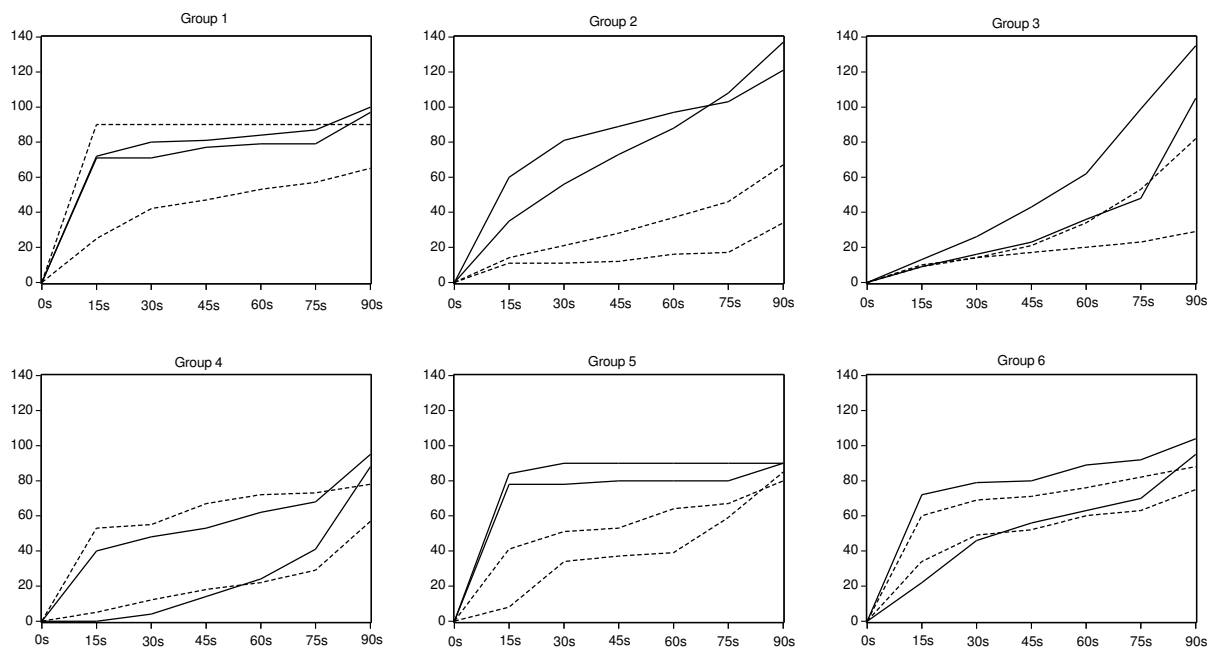

Figure 2: Individual contribution inside a period (low treatment)

We observe that the total amount of contributions is close to the cost of provision, even if it is less than $c$ in some periods or slightly larger than $c$ in other periods. When the amount exceeds the cost of provision, we find out that this is because at the end of the period (in the last 3 seconds) several individuals contribute simultaneously in order to complete the project. On average the public good is financed $65.5 \%$ of the time.

Turning to individual behaviour, Figure 2 reports the average contribution of each individual inside a period, that is, after 15, 30, 45, 60, 75 and 90 seconds. This average is calculated over the 15 last periods. As it can be seen from the figure, all subjects increase their contribution within the time interval of 90 seconds. This behaviour suggests that they have incentives to reach the cost of provision. Intuitively, the only way to obtain a positive payoff is to contribute a total amount that is greater than $c$. Acting in favour of this objective requires that subjects have to increase their individual contribution. We could distinguish two main types of behaviour: (1) individuals contributing large amount during the 15 first seconds and contributing only slightly thereafter; (2) individuals contributing low amounts during the first 75 seconds and contributing large amounts during the last 15 seconds. There are also individuals following a mixture of type 1 and type 2 behaviours.

We also observe that subjects with low WTP $\left(W T P_{i}=100\right.$; dashed lines) contribute on average $69 \%$ of their WTP that compared to subjects 

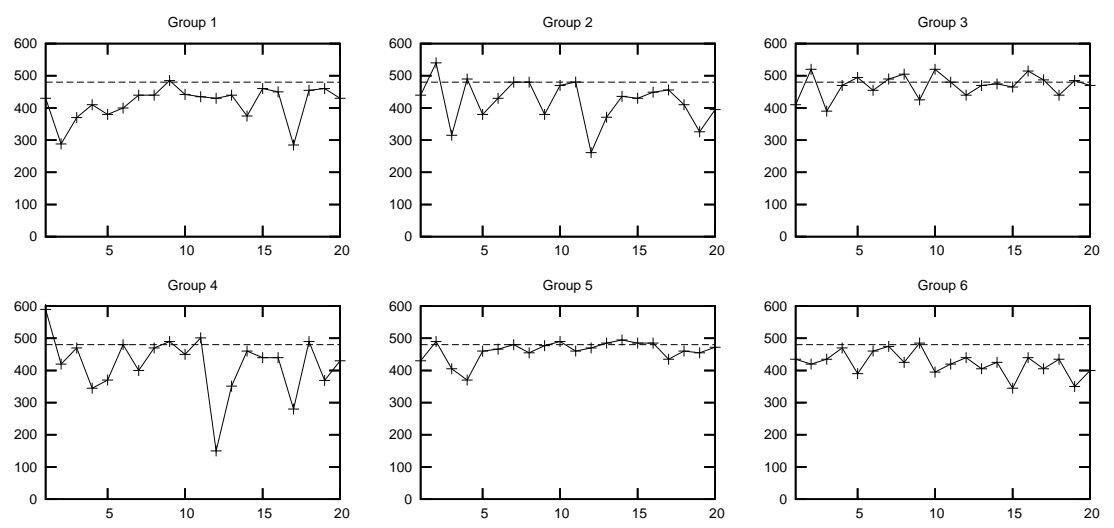

Figure 3: Contribution of each group over the 20 experimental periods (high treatment)

Table 2: Efficiency ratio (high treatment)

\begin{tabular}{|c|c|c|c|c|c|c|c|}
\hline & Group 1 & Group 2 & Group 3 & Group 4 & Group 5 & Group 6 & Average \\
\hline \hline$E f$ & 0.07 & 0.20 & 0.47 & 0.27 & 0.40 & 0.07 & 0.25 \\
\hline
\end{tabular}

with high WTP whose relative contribution is $52 \%$. This could be explained by a tendency to equal cost sharing observed in groups 5 and 6 (all members contribute nearly 90 tokens regardless their WTP). In groups 2 and 3 this tendency is mitigated by the behaviour of one individual with low WTP who commit to low contributions.

\subsection{High threshold treatment $(c=480)$}

As an alternative interpretation of the experiment, the time interval $T$ can be seen as a bargaining period in which a cost-sharing agreement might be found. A benchmark agreement in such a bargaining situation is to share the cost equally. As we saw in the previous section, there is a tendency towards equal cost sharing in some groups. What will happen if equal cost sharing is not compatible with the individual rationality of some individuals? The aim of the second treatment is to give insights to this question.

The results can be seen in Table 2 and Figure 3. We observe that the amount of contributions exceeds the cost of provision less frequently. On average the public good is financed $24.7 \%$ of the time. In other words, subjects have more difficulties to find a cost-sharing agreement. Intuitively, the reason might be that the set of agreements compatible with individual 

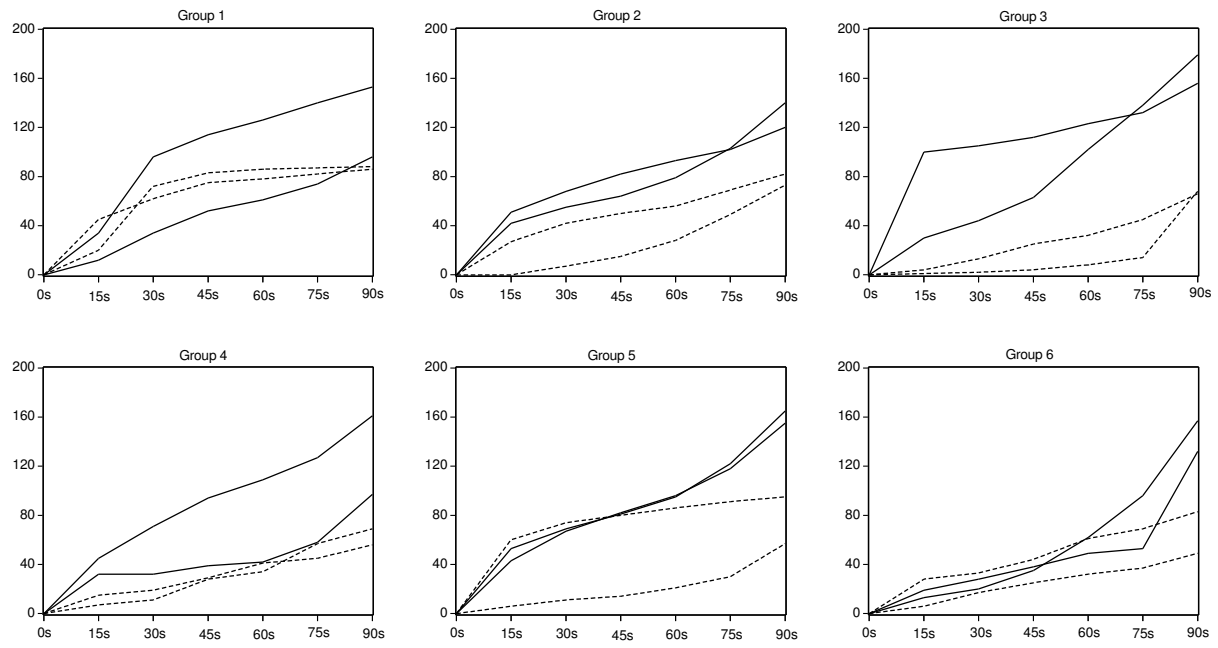

Figure 4: Individual contribution inside a period (high treatment)

rationality is now restricted making it harder to reach an agreement. Indeed, if the number of agreements that can be explored by a group during a given time interval is fixed, determined by individual's cognitive capacities for instance, restricting the set of possible agreements automatically means that the chances to find an agreement during a fixed time interval are decreased.

However, we still observe that the amount of contributions is close to the cost of provision and that in some groups and periods individuals are able to finance the public good. This means that the incentives to finance the cost are still present. This can be recognised from Figure 4, where we can see that subjects are increasing their contributions during the interval. We also observe that subjects with low WTP $\left(W T P_{i}=100\right.$; dashed lines) contribute now on average almost the same relative amount than subjects with high WTP, $72 \%$ and $71 \%$ respectively. This indicates that subjects have understood that equal cost sharing is no possible, but eventually they had no enough time to find a different cost-sharing agreement, leading to less frequent provision of the public good ${ }^{4}$. Unfortunately, because of budgetary constraints we were unable to test if increasing the contribution interval would improve the efficiency of the mechanism. This is left for future research.

\footnotetext{
${ }^{4}$ For comparison, we note that in Dorsey's (1992) experiments the time interval was fixed to 180 seconds, i.e. the double of the time given here.
} 


\section{Conclusion}

Experimental results have to be interpreted with great caution as they are sensitive to the design of the protocol and provide a limited number of independent observations such that general conclusions are not possible. Nevertheless, the experimental evidence that we provide in this paper shows that using a dynamic voluntary contribution mechanism to provide a discrete public good would induce incentives for the individuals to increase their contribution. This behaviour could be explained by the intuition that each individual have an interest to act in favour of the objective of providing the public good. In other words, we have a situation where when acting in favour of his own interest an individual also acts in favour of the interest of the society.

\section{References}

[1] Admati, A. R. and Perry, M., (1991), Joint Projects without Commitment, Review of Economic Studies, 58, 259-76.

[2] Dorsey, R. E., (1992), The voluntary contributions mechanism with real time revisions, Public Choice, 73, 261-82.

[3] Fershtman, C. and Nitzan, S., (1991), Dynamic Voluntary Provision of Public Goods, European Economic Review, 35, 1057-67.

[4] Fischbacher, U., (1999), z-Tree -Zurich Toolbox for Ready made Economic Experiments- Experimenter's Manual, Working Paper, 21, Institute for Empirical Research in Economics, University of Zurich.

[5] Gradstein, M., (1992), Time Dynamics and Incomplete Information in the Private Provision of Public Goods, Journal of Political Economy, 100, 581-97.

[6] Hichri, W., (2004), Interior Collective Optimum in a Voluntary Contribution to a Public Goods Game, Applied Economics Letters, 11(3), 135-40.

[7] Levati, V. and Neugebauer, T., (2004), An Application of the English Clock Market Mechanism to Public Goods Games, Experimental Economics, 7, 153-69.

[8] Marx, L. M. and Matthews, S. A., (2000), Dynamic Voluntary Contributions to a Public Project, Review of Economic Studies, 67, 327-58. 